\title{
COL1A1 and miR-29b show lower expression levels during osteoblast differentiation of bone marrow stromal cells from Osteogenesis Imperfecta patients
}

\author{
Carla M Kaneto ${ }^{1,5^{*}}$, Patrícia SP Lima ${ }^{3}$, Dalila L Zanette ${ }^{1,2}$, Karen L Prata ${ }^{2}$, João M Pina Neto ${ }^{1}$, Francisco JA de Paula ${ }^{4}$
} and Wilson A Silva $\mathrm{Jr}^{1,2}$

\begin{abstract}
Background: The majority of Osteogenesis Imperfecta (OI) cases are caused by mutations in one of the two genes, COLIA1 and COL1A2 encoding for the two chains that trimerize to form the procollagen 1 molecule. However, alterations in gene expression and microRNAs (miRNAs) are responsible for the regulation of cell fate determination and may be evolved in Ol phenotype.

Methods: In this work, we analyzed the coding region and intron/exon boundaries of COLIA1 and COL1A2 genes by sequence analysis using an ABI PRISM 3130 automated sequencer and Big Dye Terminator Sequencing protocol. COLIA1 and miR-29b expression were also evaluated during the osteoblastic differentiation of mesenchymal stem cell (MSC) by qRT-PCR using an ABI7500 Sequence Detection System.

Results: We have identified eight novel mutations, where of four may be responsible for Ol phenotype. COL1A1 and miR-29b showed lower expression values in OI type I and type III samples. Interestingly, one type III OI sample from a patient with Bruck Syndrome showed COL1A1 and miR-29b expressions alike those from normal samples.

Conclusions: Results suggest that the miR-29b mechanism directed to regulate collagen protein accumulation during mineralization is dependent upon the amount of COL1A1 mRNA. Taken together, results indicate that the lower levels observed in Ol samples were not sufficient for the induction of miR-29b.
\end{abstract}

Keywords: Osteogenesis Imperfecta, miR-29b, COL1A1, Osteogenesis, Mesenchymalstem cells

\section{Background}

Osteogenesis Imperfecta (OI) (OMIM \#166200) is a heterogeneous group of inherited disorders characterized by increased bone fragility and clinical severity ranging from mild to lethal [1]. Four types of OI have been described based on clinical phenotypes and histological findings [2], but more recently, at least three additional groups of patients who had a clinical diagnosis of the disorder but who presented clearly distinct features were delineated [3]. The clinical spectrum is wide, ranging

\footnotetext{
* Correspondence: carlakaneto@gmail.com

${ }^{1}$ Department of Genetics, Medical School of Ribeirão Preto, Universidade de São Paulo, Ribeirão Preto, São Paulo, Brazil

${ }^{5}$ Department of Biological Science, Universidade Estadual de Santa Cruz UESC - Ilhéus, Rodovia Jorge Amado, Km16, 45662-900 Ilhéus, BA, Brazil Full list of author information is available at the end of the article
}

from few fractures, in mild cases, to multiple fractures and perinatal lethality [4]. Most patients have mutations in the COL1A1 or COL1A2 genes, which encode collagen 1 , which in turn is the major component of the bone matrix [5]. Collagen 1, an extra-cellular matrix protein, has two $\alpha 1$ and one $\alpha 2$ collagen chains forming a triple helix structure. However, skeletal development and bone remodeling also require stringent control of gene expression for osteoprogenitor lineage cells to advance through stages of differentiation whereas little is known about this in OI [6].

Recent reports identify critical roles of microRNAs (miRNAs) as regulators of gene expression either by inhibiting the translation or by stimulating the degradation of target mRNAs in the regulation of cell fate 
determination [7]. Additionally, miRNA profiling during the initial stages of osteoblast phenotype development showed the up-regulation of a limited cohort of miRNAs that have predicted targets for muscle differentiation [8]. Other works have described the importance of microRNAs in controlling transcriptions factors [9] and noncollagen extracellular matrix proteins leading to inhibition of the osteogenic process [10]. On the other hand, some microRNAs are responsible for the induction of osteogenesis [11]. MiR-29b, for example, supports osteoblast differentiation through several mechanisms which decrease the activity of COL1A1, COLSA3 and COL4A2 and regulate collagen protein accumulation during mineralization when miR-29b reaches peak levels [6]. There is no information regarding the expression of microRNAs in patients with Osteogenesis Imperfecta.

In this work, the analysis of COL1A1 and COL1A2genes in five unrelated patients with type I and type III OI identified a total of 8 novel mutations, whereas the analysis from miR-29b expression led us to propose that it does not regulate COL1A1 levels during osteoblast differentiation in OI in comparison to normal mesenchymal stem cells.

\section{Methods}

The mononuclear cell fractions were derived from the bone marrow of eight different donors [five patients with Osteogenesis Imperfecta (MOOI1-MOOI5) and three normal donors (MON1-MON3)] who gave consent after full information and approval by the Ethics Committee of the Medical School of Ribeirão Preto Hospital, University of São Paulo (Number: 10188/2007). All MNC (mononuclear cells) were isolated and MSC were cultivated as previously described [12] until the third passage, when osteogenic differentiation was induced with an expansion medium supplemented with $0.01 \mathrm{mM}$ dexamethasone, $200 \mu \mathrm{M}$ ascorbic-acid-2-phosphate and $10 \mathrm{mM} \beta$-glycerophosphate. Genomic DNA was extracted from mesenchymal stem cells using the Wizard Genomic DNA Purification Kit (Promega). DNA sequencing of PCR-amplified COL1A1 and $C O L 1 A 2$ gene fragments covering the entire coding region and intron/exon boundaries was carried out using an $\mathrm{ABI}$ PRISM 3130 automated sequencer and the Big Dye Terminator Sequencing protocol. All primer sequences used in the PCR amplification of COL1A1 and COL1A2 are available as an Additional file 1. RNA was harvested at seven time points during the osteogenic differentiation period (D0, D + $1, \mathrm{D}+2, \mathrm{D}+7, \mathrm{D}+12, \mathrm{D}+17$ and $\mathrm{D}+21)$. Total RNA was isolated with TRIzol reagent (Invitrogen) and concentration was determined by photometric measurements. A High Capacity cDNA Reverse Transcription Kit (Applied Biosystems) was used to synthesize cDNA from $2 \mu \mathrm{g}$ of RNA, following manufacturer's recommendations. The primer sequences used in the PCR amplification of COL1A1 are available as an Additional file 1. qRT-PCR amplification mixtures contained 20 ng template cDNA, 2X Power SYBR Green Master mix (10 $\mu \mathrm{L})$ (Applied Biosystems) and 400$600 \mathrm{nM}$ forward and reverse primers in a final volume of $20 \mu \mathrm{L}$. TaqMan ${ }^{\circ}$ MicroRNA Assays (Applied Biosystems) were used to assess miR-29b expression levels and included two steps: reverse transcription and real-time PCR. The total RNA (2.5 ng/reaction) from samples was reversetranscribed with specific looped RT primers. $15 \mu \mathrm{L}$ reactions, in turn, were performed using reagents from the High-Capacity cDNA Archive Kit (PN 4322171, AppliedBiosystems) and 1.9 U RNase inhibitor (PNN8080119, Applied Biosystems) and were and incubated for 30 minutes at $16^{\circ} \mathrm{C}, 30$ minutes at $42^{\circ} \mathrm{C}$, and 5 minutes at $85^{\circ} \mathrm{C}$. As for the real-time PCR step, $4.5 \mu \mathrm{L}$ 1:5 diluted cDNA samples were used as templates in $10 \mu \mathrm{L}$ reactions containing primers and probes for miR-29b, according to manufacturer instructions. All reactions were run in duplicate on an ABI7500 Sequence Detection System (Applied Biosystems, Foster City, CA, USA) under the following conditions: $95^{\circ} \mathrm{C}$, for 10 minutes, followed by 40 cycles at $95^{\circ} \mathrm{C}$ for 15 seconds, and $60^{\circ} \mathrm{C}$, for 1 minute. Total RNA input was normalized based on the $\mathrm{Ct}$ values obtained for RNU6B, which is a nucleolar RNA used as an endogenous control in this type of analysis. Experiments with coefficients of variation greater than $5 \%$ were excluded. As regards COL1A1 reactions, each run was completed with a melting curve analysis so as to confirm the specificity of amplification and the lack of primer dimers. Reactions were carried out in triplicates and a no-template control was also included. The relative quantification of gene expression was carried out using the mathematical model described in [13].

\section{Results}

All 51 coding exons in the COL1A1 gene and 52 exons in the COL1A2 gene were analyzed by DNA sequencing. A total of 8 different mutations were identified in the type I collagen genes of all patients. These mutations are summarized in Figure 1. All the mutations outlined here are novel. In COL1A1: 1 missense mutation (p. Gly290Glu) have been identified in patient MOOI3, 1 nonsense mutation (Arg1026Ter) have been identified in patient MOOI1, 1 out-of-frame insertion mutation (p. Leu69GlufsX74) have been identified in patient MOOI4 and 2 silent mutations were identified in patient MOOI5. In COL1A2: 1 missense mutation (p. Gly835Ser) have been identified in patient MOOI2 and 2 different silent mutations were identified in patient MOOI2 and MOOI5. The distribution of mutations in our patients is similar to that reported in the literature, with glycine substitutions in the helical domain, resulting in severe phenotype (Table 1). In these cases, structurally altered chains are inserted into the collagen 1 protein and disturb the formation of the triple helix, thus affecting the functions 


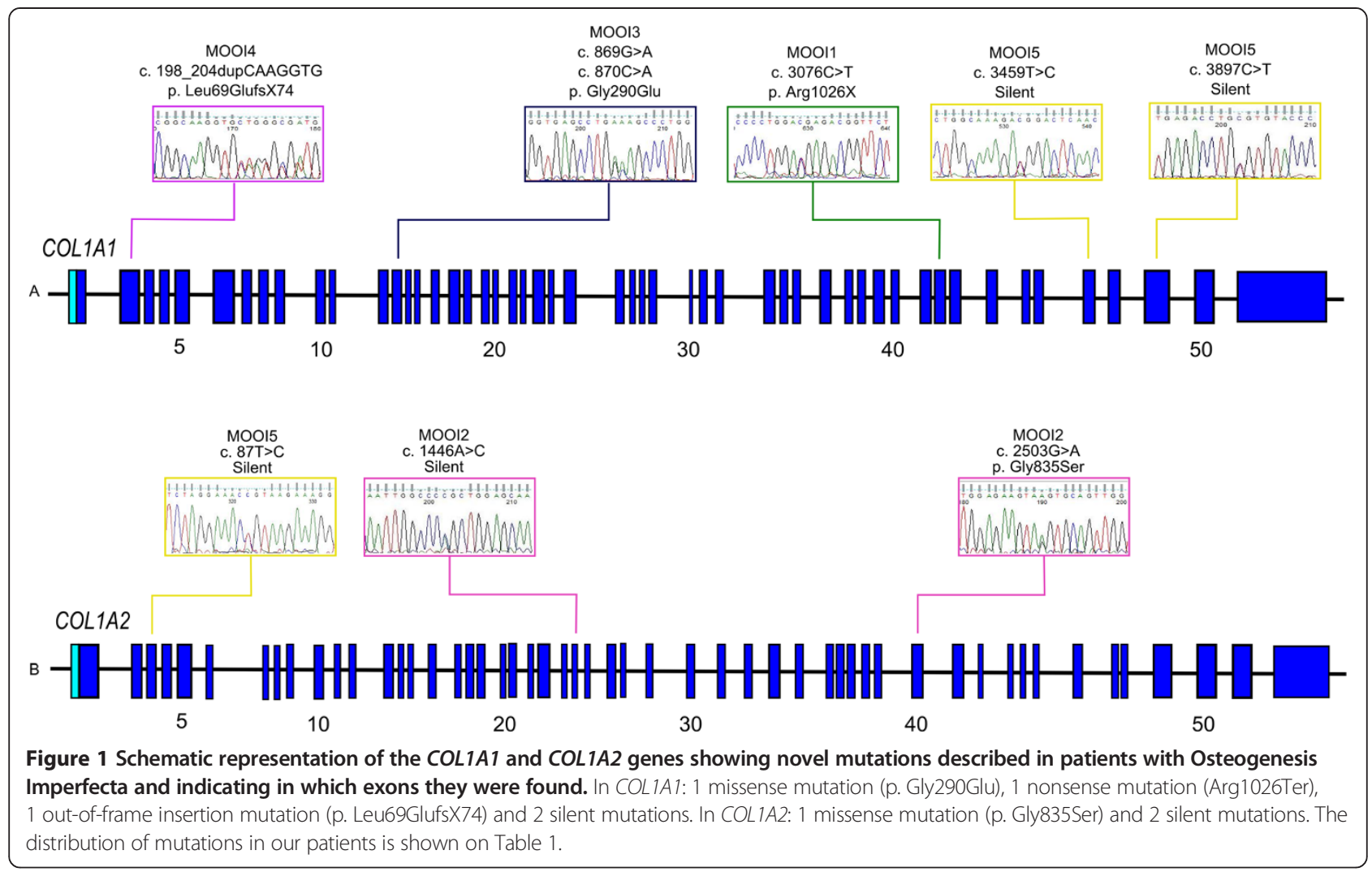

of normal chains in a secondary manner (referred to as a dominant negative effect). Nonsense mutations in COL1A1 typically result in unstable gene products and reduced collagen synthesis, which is yet qualitatively normal. This haploinsufficiency of COL1A1 results in mild forms of OI [14].

In patient OI5 with Bruck Syndrome (BS) (a very rare disorder characterized by Osteogenesis Imperfecta and arthrogryposis multiplex congenital), 3 silent mutations were detected and were considered as non-pathogenic, as they do not alter amino acids. Interestingly, miR-29b and COL1A1 expression were severely reduced in both type I and type III OI patients (Figure 2), suggesting that miR-29b expression is not a requirement for supporting osteoblast differentiation.

\section{Discussion}

It is possible that extracellular signals contribute to microRNA regulation during differentiation, supporting a role for microRNAs during MSC development [15]. Suh et al. (2012) have investigated the role of microRNAs in a

Table 1 Clinical features and detected mutations of OI patients

\begin{tabular}{|c|c|c|c|c|}
\hline Clinical data & MOOI-I 1 & MOOI-III 2 & MOOI-III 3 & MOOI-I 4 \\
\hline Ol Type ${ }^{* 1}$ & 1 & III & III & 1 \\
\hline Gender & M & $\mathrm{F}$ & M & $\mathrm{F}$ \\
\hline Age (years) & 26 & 23 & 15 & 41 \\
\hline Family history & No & No & No & No \\
\hline Number of fractures & +30 & +30 & +30 & -30 \\
\hline Bone deformities & Yes & Yes & Yes & Yes \\
\hline Blue sclera & Yes & Yes & Yes & Yes \\
\hline Dentinogenesis imperfecta & Yes & Yes & Yes & Yes \\
\hline Hearing loss & No & No & Yes & Yes \\
\hline Mutation & $\begin{array}{c}\text { COL1A1 c.3076C > } \\
\text { T, Arg1026X }\end{array}$ & $\begin{array}{c}\text { COL1A2 c.2503G > } \\
\text { A, Gly835Ser }\end{array}$ & $\begin{array}{c}\text { COL1A1 c. 869G > } \\
\text { A, Gly290Glu }\end{array}$ & $\begin{array}{c}\text { COL1A1 c.198_204dupCAAGGTG } \\
\text { Leu69Glu-fsX74 }\end{array}$ \\
\hline
\end{tabular}

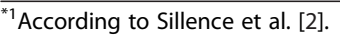




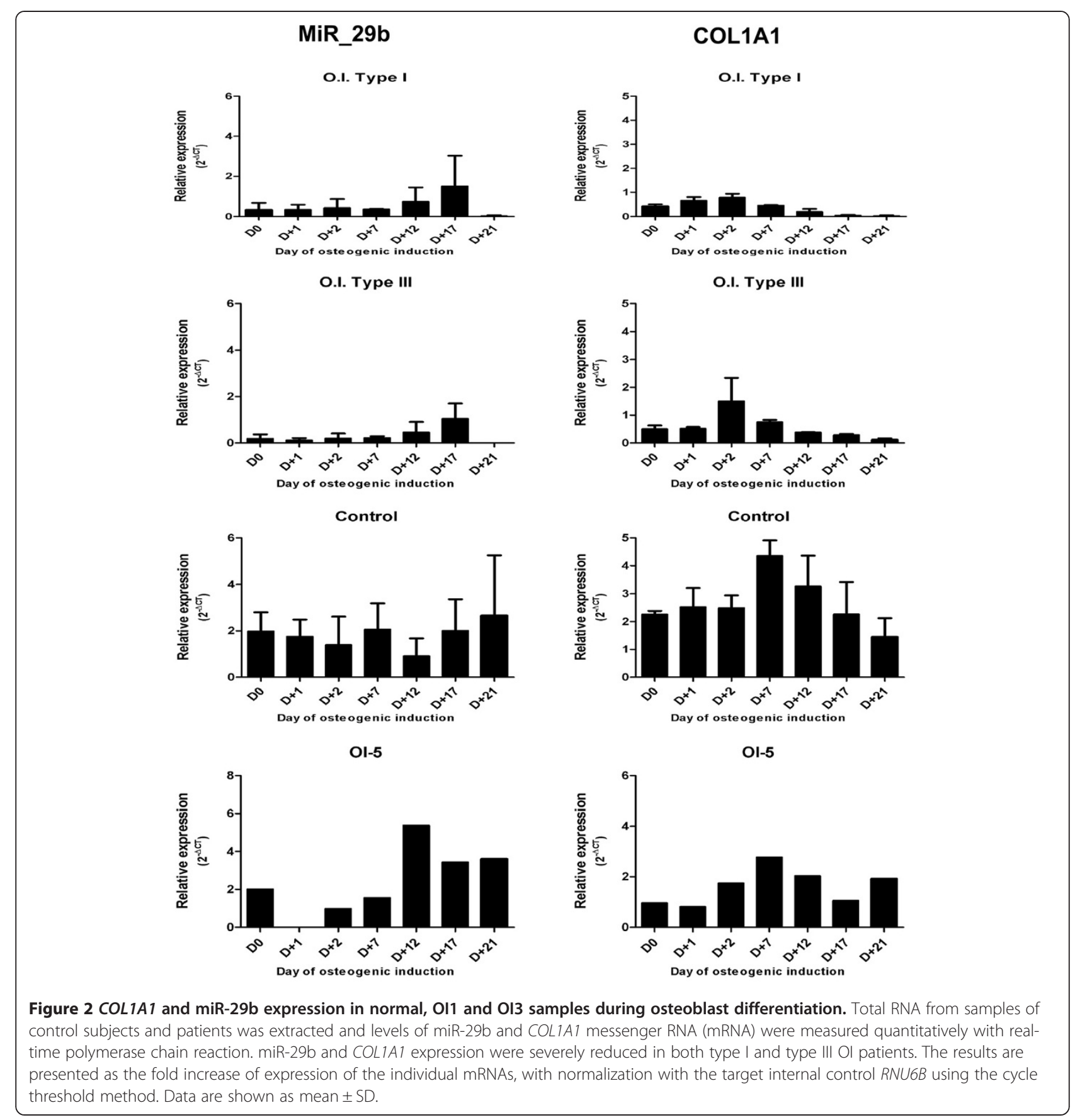

fibroblast model of quiescence and discovered that microRNA expression is broadly and similarly altered by two different quiescence signals: contact inhibition and serum withdrawal. They further found that microRNAs regulate some of the changes in gene expression and cellular function associated with quiescence, as well as the transition between proliferation and quiescence [16]. We therefore hypothesized that the amount of mRNA and the quality of secreted collagen could be those signals. Apparently, the miR-29b mechanism for regulating collagen protein accumulation during mineralization is dependent upon the amount of COL1A1 mRNA. The lower levels observed in OI samples are not sufficient for miR-29b induction. However, no direct interaction between COL1A1 and miR-29b has been examined in this study.

The pattern of microRNA expression in MSC is distinct from that in pluripotent stem cells while specific populations of microRNAs are regulated in MSC during differentiation targeted towards specific cell types. Understanding the key regulatory pathways and molecules 
either involved in maintaining MSC in their undifferentiated state or during the process of differentiation allows for a better handle on expanding these cells for therapeutic applications on a broad scale [17].

The data obtained for BS patient revealed miR-29b and COL1A1 expression profiles similar to those found in normal samples. Studies of Bruck syndrome have found normal secretion of collagen 1 in three families, whereas no mutations have been detected in the COL1A1 and COL1A2 genes [18]. In addition to the normal miR-29b and COL1A1 expression levels, the absence of pathogenic mutations in COL1A1 and COL1A2 suggest that miR29b expression could be associated to COL1A1 expression levels.

\section{Conclusions}

Taken together, our study suggests that the miR-29b mechanism for regulating collagen protein accumulation during mineralization is dependent upon the amount of COL1A1 mRNA. Results indicate that the lower levels observed in OI samples are not sufficient for the induction of miR-29b, but no direct interaction between COL1A1 and miR-29b has been examined in this study. Furthermore, we have presented the clinical and molecular features of four patients with novel, so far undescribed mutations in COL1A1 and COL1A2 genes that further illustrate the complexity, but that can contribute to better understand genotype-phenotype correlations for OI and related connective tissue disorders.

\section{Additional file}

Additional file 1: Sequences of primers used for PCR, sequencing and qRT-PCR.

\section{Competing interests}

The authors declare that they have no competing interests.

\section{Authors' contributions}

CMK and PSPL performed the experiments on cell culture preparations. In the same way, CMK also conducted all experiments, differentiations, mutational analyses and gene expressions. DLZ did microRNA expression assays. KLP was responsible for collecting bone marrow samples and JMPN, FJAP and WASJ conceived of the study and participated in its design and coordination, and helped to draft the manuscript. All authors read and approved the final manuscript.

\section{Acknowledgements \\ Support for this work was provided by the Brazilian agencies FAPESP, CNPq, and Center for Cell-based Therapy. We are also thankful to Cristiane Ayres Ferreira and Adriana Aparecida Marques for their excellent technical assistance.}

\section{Author details}

'Department of Genetics, Medical School of Ribeirão Preto, Universidade de São Paulo, Ribeirão Preto, São Paulo, Brazil. ${ }^{2}$ Regional Blood Center of Ribeirão Preto and National Institute of Science and Technology in Cell Therapy, Ribeirão Preto, Brazil. ${ }^{3}$ Department of Natural Science, Universidade Estadual do Sudoeste da Bahia, Vitória da Conquista, Bahia, Brazil. ${ }^{4}$ Department of Clinical Medicine, Faculdade de Medicina de Ribeirão Preto, Universidade de São Paulo, Ribeirão Preto, São Paulo, Brazil. ${ }^{5}$ Department of
Biological Science, Universidade Estadual de Santa Cruz - UESC - Ilhéus, Rodovia Jorge Amado, Km16, 45662-900 Ilhéus, BA, Brazil.

Received: 3 December 2013 Accepted: 17 April 2014 Published: 27 April 2014

\section{References}

1. Horwitz EM, Prockop DJ, Fitzpatrick L a, Koo WW, Gordon PL, Neel M, Sussman M, Orchard P, Marx JC, Pyeritz RE, Brenner MK: Transplantability and therapeutic effects of bone marrow-derived mesenchymal cells in children with osteogenesis imperfecta. Nat Med 1999, 5:309-313.

2. Sillence DO, Senn a, Danks DM: Genetic heterogeneity in osteogenesis imperfecta. J Med Genet 1979, 16:101-116.

3. Rauch F, Glorieux FH: Osteogenesis imperfecta. Lancet 2004, 363:1377-1385.

4. Reuter MS, Schwabe GC, Ehlers C, Marschall C, Reis A, Thiel C, Graul-Neumann $\mathrm{L}$ : Two novel distinct COL1A2 mutations highlight the complexity of genotype-phenotype correlations in osteogenesis imperfecta and related connective tissue disorders. Eur J Med Genet 2013, 56:1-5.

5. Pollitt R, McMahon R, Nunn J, Bamford R, Afifi A, Bishop N, Dalton A: Mutation analysis of COL1A1 and COL1A2 in patients diagnosed with osteogenesis imperfecta type I-IV. Hum Mutat 2006, 27:716.

6. Li Z, Hassan MQ, Jafferji M, Aqeilan Rl, Garzon R, Croce CM, Van Wijnen AJ, Stein JL, Stein GS, Lian JB: Biological functions of miR-29b contribute to positive regulation of osteoblast differentiation. I Biol Chem 2009, 284:15676-15684.

7. Schoolmeesters A, Eklund T, Leake D, Vermeulen A, Smith Q, Force Aldred S, Fedorov $Y$ : Functional profiling reveals critical role for miRNA in differentiation of human mesenchymal stem cells. PloS One 2009, 4:e5605.

8. Li Z, Hassan MQ, Volinia S, Van Wijnen AJ, Stein JL, Croce CM, Lian JB, Stein GS: A microRNA signature for a BMP2-induced osteoblast lineage commitment program. Proc Natl Acad Sci U S A 2008, 105:13906-13911.

9. Huang J, Zhao L, Xing LCD: MicroRNA-204 regulates Run $\times 2$ protein expression and mesenchymal progenitor cell differentiation. Stem Cells 2010, 28:357-364.

10. Kapinas K, Kessler CB, Delany AM: miR-29 Suppression of Osteonectin in Osteoblasts: regulation during differentiation and by Canonical Wnt Signaling. J Cell Biochem 2010, 108:216-224.

11. Kim YJ, Bae SW, Yu SS, Bae YC, Jung JS: miR-196a regulates proliferation and osteogenic differentiation in Mesenchymal stem cells derived from human adipose tissue. J Bone Miner Res 2009, 24:816-825.

12. Silva WA Jr, Covas DT, Panepucci RA, Proto-Siqueira R, Siufi JL, Zanette DL, Santos ARZM: The profile of gene expression of human marrow mesenchymal stem cells. Stem Cells 2003, 21:661-669.

13. Ventura A, Young AG, Winslow MM, Lintault L, Meissner A, Erkeland SJ, Newman J, Bronson RT, Crowley D, Stone JR, Jaenisch R, Sharp P a, Jacks T: Targeted deletion reveals essential and overlapping functions of the miR-17 through 92 family of miRNA clusters. Cell 2008, 132:875-886.

14. Willing MC, Deschenes SP, Scott D a, Byers PH, Slayton RL, Pitts SH, Arikat H, Roberts EJ: Osteogenesis imperfecta type I: molecular heterogeneity for COL1A1 null alleles of type I collagen. Am J Hum Genet 1994, 55:638-647.

15. Goff LA, Boucher S, Ricupero CL, Fenstermacher S, Chase L, Adams C, Chesnut J, Lakshmipathy U, Hart RP: Differentiating human multipotent mesenchymal stromal cells regulate microRNAs: prediction of microRNA regulation by PDGF during osteogenesis. Exp Hematol 2009, 36:1354-1369.

16. Suh EJ, Remillard MY, Legesse-Miller A, Johnson EL, Lemons JM, Chapman TR, Forman JJ, Kojima M, Silberman ES, Coller H a: A microRNA network regulates proliferative timing and extracellular matrix synthesis during cellular quiescence in fibroblasts. Genome Biol 2012, 13:R121.

17. Sakai D, Mochida J, Yamamoto Y, Nomura T, Okuma M, Nishimura K, Nakai T, Ando K, Hotta T: Transplantation of mesenchymal stem cells embedded in Atelocollagen ${ }^{\circledast}$ gel to the intervertebral disc: a potential therapeutic model for disc degeneration. Biomaterials 2003, 24:3531-3541.

18. Breslau-Siderius EJ, Engelbert RH, van der Pals G SJ: Bruck syndrome: a rare combination of bone fragility and multiple congenital joint contractures. J Pediatr Orthop 1998, 7:35-38.

doi:10.1186/1471-2350-15-45

Cite this article as: Kaneto et al: COL1A1 and miR-29b show lower expression levels during osteoblast differentiation of bone marrow stromal cells from Osteogenesis Imperfecta patients. BMC Medical Genetics 2014 15:45. 